\title{
Titanium uptake and incorporation into silica nanostructures by the diatom Pinnularia sp. (Bacillariophyceae)
}

\author{
Matilde Skogen Chauton • Lotte M. B. Skolem • \\ Lasse Mork Olsen • Per Erik Vullum • John Walmsley • \\ Olav Vadstein
}

Received: 3 June 2014 / Revised and accepted: 3 July 2014 / Published online: 24 July 2014

(C) The Author(s) 2014. This article is published with open access at Springerlink.com

\begin{abstract}
Diatoms are an ecologically successful group within the phytoplankton, and their special feature is a biofabricated silica cell encasement called a frustule. These frustules attract interest in material technology, and one potential application is to use them in solar cell technology. The silica frustule with its nanoscaled pattern is interesting per se, but the utility is enhanced if we succeed in incorporating other elements. Titanium is an interesting element because its oxide is a semi-conductor with a high band gap. However, doping with relevant elements through bioincorporation is challenging, and it is necessary to understand the biology involved in element uptake and incorporation. Here we present data on bioincorporation of $\mathrm{Ti}$ into the silica frustules of the pennate diatom Pinnularia sp. (Ehrenberg) and show that the distribution of the incorporated $\mathrm{Ti}$ is inhomogeneous both between and within valves. More than a tenfold increase of Ti in newly synthesised valves was achieved, and increased Ti around the pores was confirmed by both EDS and EELS analyses. HAADF STEM spectroscopy revealed a grainy surface with amorphous silica particles of 4 to $5 \mathrm{~nm}$ in size. These observations are explained by what is known from the physicochemical processes involved in biosilification and frustule formation, looking into it from a biological point of view.
\end{abstract}

Keywords Silica $\cdot$ Titanium $\cdot$ Diatom $\cdot$ Bioincorporation · Frustulem $\cdot$ Nanostrucuture

\footnotetext{
M. S. Chauton $(\bowtie) \cdot$ L. M. B. Skolem • L. M. Olsen • O. Vadstein Department of Biotechnology, Norwegian University of Science and Technology (NTNU), SemSelands veg 6/8, 7491 Trondheim, Norway

e-mail: matilde.chauton@nt.ntnu.no

P. E. Vullum · J. Walmsley

SINTEF Materials and Chemistry, Postboks 4760 Sluppen,

7465 Trondheim, Norway
}

\section{Introduction}

Diatoms possess a cell encasement called the frustule, made of amorphous (i.e. non-crystalline) silica. The frustule consists of two valves, ornamented with species-specific patterns of pores and ribs on meso- and nanoscale dimensions. When the diatom cell divides each new cell will retain one old valve and synthesise one new valve. The actual role of the frustule remains a topic for discussion, but possible functions are light transmission, nutrient transport, gas exchange and grazer or virus protection. Amorphous silica is in principle transparent to visible light (which the living diatom use for photochemical energy synthesis), and it is suggested that the pore pattern provides a photonic crystal function that results in light focussing and transport into the chloroplasts (Yamanaka et al. 2008; De Stefano et al. 2009; Sclafani et al. 2013).

When diatoms grow exponentially (i.e. resource-unlimited growth), silicic acid $\left(\mathrm{SiOH}_{4}\right)$ is actively transported via silica transporters (SITs) into the cytoplasm and then via transport vesicles into silica deposition vesicles (SDVs) (Annenkov et al. 2013). This process involves active transport against a concentration gradient from cytosol into the SDV and a $\mathrm{pH}$ gradient because the inside of the SDV has a lower $\mathrm{pH}$. In the $\mathrm{SDV}$, silicon $(\mathrm{Si})$ polymerizes to silica $\left(\mathrm{SiO}_{2}\right)$, and small building blocks are created. Exactly how these polymers are combined to form a frustule remains unknown (Del Amo and Brzezinski 1999; Zurzolo and Bowler 2001). Frustule construction is most probably a combination of genetically expressed $\mathrm{Si}$ transporter proteins that are involved in the transport of Si into the cell (Thamatrakoln and Hildebrand 2007) and post-translationally modified peptides (silaffins, silacidins) and long-chained polyamines involved in Si polymerization and construction of the frustule (Mock et al. 2008; Spinde et al. 2011); Kinrade et al. (2002) observed a transient organosilicon complex in the diatom Navicula pelliculosa: hexavalent $\mathrm{Si}$ was coordinated to nitrogen, but it was not 
possible to determine the localization of these complexes or if they were involved in frustule synthesis.

The highly modifiable frustule surface properties has been exploited in drug delivery technology (Aw et al. 2012), and the mesoporous frustule material has been applied as photocatalyst templates (Mao et al. 2014; He et al. 2013). The use of biogenic Si from diatoms in solar cell technology has been suggested, and the idea is extended to use the intact frustule itself and take advantage of the nanoscaled patterns of pores and rib structures (Jeffryes et al. 2011; Toster et al. 2013). The concentration of $\mathrm{Si}$ in aquatic environments is many times higher than other comparable elements, and the frustule composition likely reflects the availability of $\mathrm{Si}$ and also other elements: for example, the concentration of anions such as phosphorus is quite high in the frustules possibly because it plays a role in the formation of $\mathrm{Si}$ nanoparticles during frustule synthesis (Hildebrand 2008). From a material point of view, on the other hand, there are other elements such as in the semi-conductor $\mathrm{TiO}_{2}$ that would enhance the functionality of the frustule.

Increased concentrations of functional elements can be achieved by metabolic doping in living cells or by postmodifications such as thermal annealing. $\mathrm{TiO}_{2}$ (Jeffryes et al. 2008; Lang et al. 2013) and $\mathrm{GeO}_{2}$ (Gale et al. 2011) have been incorporated by bio-uptake or deposited on the frustules post-cleaning. $\mathrm{GeO}_{2}$ has been shown to inhibit diatom growth (Shea and Chopin 2007) and to interfere with frustule synthesis (Basharina et al. 2012). The uptake of other elements may be regulated as a function of concentrations, and there will be biological limits to the amount of a specific element that can be incorporated. Ti is not considered an essential element to organisms, but it has been discussed whether this is due to the fact that it is readily available, so we fail to detect its essentiality, or if it is truly non-essential. It is, however, bioactive (Buettner and Valentine 2012), and another consideration when trying to understand biogenic incorporation of various elements into the silica frustule is the potential harmful effects of, for example, $\mathrm{TiO}_{2}$ nanoparticles. The semi-conductive properties of $\mathrm{TiO}_{2}$ nanoparticles is desired in solar cells, but in living cells they are toxic in combination with UV light because the nanoparticles can lead to the formation of ROS (Miller et al. 2012). However, microalgae have a naturally high antioxidant protection because of their photosynthetic activity and concurrent oxygen formation. With the emerging field of nanomaterials, it has been shown that nanoparticles can accumulate in organelles such as the mitochondria and disrupt the electron transport chain with increased production of superoxide radicals $(\mathrm{Li}$ et al. 2003). It is therefore natural to assume that the uptake and transport of $\mathrm{Ti}$ into live cells is a controlled process in some way, where the Ti is directed to cell compartments where it is not damaging, e.g. the SDVs. No specialized Ti uptake or deposition proteins are known for diatoms, but mineralization of $\mathrm{TiO}_{2}$ by recombinant silaffins or silicateins has been demonstrated (Sumerel et al. 2003; Cole et al. 2006; Kroger et al. 2006).

Here we present data on uptake and incorporation of $\mathrm{Ti}$ in frustules of Pinnularia sp. (Ehrenberg), and we show that the photophysiology of Pinnularia cells was not adversely affected by the experimental setup and that Ti concentration is strongly enhanced in certain parts of the newly formed valves. Our work is a follow-up of Jeffryes et al. (2008) as we address some points raised in their discussion, in addition to providing new data on $\mathrm{SiO}_{2}$ particle size and the variability of Ti measurements. Our observations are interpreted in light of what is known about element uptake and deposition in living cells, and we discuss how this knowledge can be used to better understand both the biological function of a frustule and how to modify the frustule as a functional material.

\section{Materials and methods}

Cultivation, photophysiology and biomass

Pinnularia sp. (UTEX B679) was grown in filtered, autoclaved seawater amended with nutrients according to Guillard's f/2-recipe for all elements except $\mathrm{Si}$, which was reduced to $50 \%$. The natural seawater used here contains around $4 \mu \mathrm{M}$ Si. Light was set at $130 \mu \mathrm{mol}$ photons $\mathrm{m}^{-2} \mathrm{~s}^{-1}$ and 16:8 light/dark cycles. A smaller culture was kept for more than ten generations with regular dilutions to allow acclimatization before Ti uptake, and incorporation experiments were performed on larger experimental cultures. The cultivation setup consisted of borosilicate culture vessels of cylindrical shape with conical ends, with a diameter of $8 \mathrm{~cm}$ and a height of $50 \mathrm{~cm}$ (approximately 1,500 mL working volume). The volume of the experimental cultures was 1.11.2 L. Silicone stoppers and silicone hoses were used to ventilate the cultures, which were placed in a growth cabinet at $20^{\circ} \mathrm{C}$. Pressurized air (provided by aquarium pumps) was used to mix the cultures, using a gentle stream of bubbles from the bottom of the culture vessels. Macronutrients $\mathrm{NO}_{3}, \mathrm{PO}_{4}$ and $\mathrm{Si}$ were measured at selected time points during the acclimatization period to verify surplus (or in the case of $\mathrm{Si}$, limitation before the experiments were initiated) using Merck Spectroquant test kits and SpectroquantPharo 100 spectrophotometer.

Instantaneous chlorophyll fluorescence $\left(F_{\mathrm{t}}\right)$ and quantum yield $\left(Q_{\mathrm{y}}\right)$ was monitored using a dual-mode AquaPen AP 100 (Photon Systems Instruments flurometer) to assess the biomass changes and photophysiological condition of the cells during cultivation and experiments. Pinnularia sp. has a tendency to cluster, and cell counts can be biased. Therefore, the consumed $\mathrm{Si}$ and the $F_{\mathrm{t}}$ measurements were used to assess changes in the biomass. 


\section{Ti uptake and incorporation experiments}

Ti uptake experiments were initiated when the Si concentration in the medium was $<0.5 \mu \mathrm{mol} \mathrm{L}{ }^{-1}$ for two consecutive days and the cell numbers did not increase any further. $\mathrm{Si}$ limitation is known to induce cell cycle arrest in diatoms (Brzezinski et al. 1990), and the populations were expected to be highly synchronized at the start of the experiment. Visual inspection of samples at the start of the experiment showed some size differences, with cells of mainly three different sizes and with a mean cell size of $35.2 \mu \mathrm{m}(\mathrm{CV} 8.2 \%, n=67)$. A large number of paired cells were observed, in accordance with the $\mathrm{Si}$ limitation and cell cycle arrest before the final cell separation. The experiment was performed two times. Pure crystalline $\mathrm{Ti}(\mathrm{OH})_{4}$ was made according to Jeffryes et al. (2008), and a stock solution was prepared by dissolving the $\mathrm{Ti}(\mathrm{OH})_{4}$ in concentrated $\mathrm{HCl}$ (37 wt.\%) with continuous stirring on a hot plate $\left(80^{\circ} \mathrm{C}\right)$. The stock solution was diluted with heated $\left(80^{\circ} \mathrm{C}\right)$ deionised water to a final concentration of $500 \mathrm{mM} \mathrm{HCl} / 0.36 \mathrm{mM}$ Ti. A solution of $\mathrm{Na}_{2} \mathrm{SiO}_{3} \cdot 9 \mathrm{H}_{2} \mathrm{O}$ in $500 \mathrm{mM} \mathrm{NaOH}$ was made to balance the acidic Ti solution (final concentration $6.2 \mathrm{mM} \mathrm{Si}$ ), and the two solutions were added in equal volumes to the experimental cultures using two Cole-Parmer 94900 Syringe pumps. The total Si and Ti solution volume was added drop-wise over $10 \mathrm{~h}$, and the $\mathrm{pH}$ was between 8.0 and 8.4 during the experiments.

Control experiments were performed with (a) only medium (without cells) and addition of approximately $3.8 \mu \mathrm{mol} \mathrm{L} \mathrm{L}^{-1} \mathrm{Ti}$ and $160 \mu \mathrm{mol} \mathrm{L} \mathrm{L}^{-1} \mathrm{Si}$ to verify that both $\mathrm{Si}$ and $\mathrm{Ti}$ are recovered with the medium and do not adsorb to the glassware and (b) a culture of Pinnularia sp. grown in plastic bottles to determine the background of $\mathrm{Ti}$ in frustules without the borosilicate glassware as a possible source of Ti.

After centrifuging to remove the culture medium, organic material was removed from the biosilica using SDS/EDTA (50 $\mathrm{mg} \mathrm{L}^{-1}$ in $100 \mathrm{mM}$ EDTA solution), and the frustules were stored in methanol at $-20{ }^{\circ} \mathrm{C}$ until analysed. One of the frustule samples from the Ti uptake experiments was chosen for determination of Ti by ICP-MS and analytical transmission electron microscopy (TEM). Control samples without addition of Ti were also analysed.

\section{Measurements of Ti by ICP-MS}

High-resolution inductively coupled plasma mass spectrometry (HR ICP-MS; ELEMENT 2 instrument from Thermo Electronics) was used to determine the concentrations of $\mathrm{Ti}$ in seawater (background), cultivation medium and frustule samples, with and without incorporated Ti. A total of $2 \mathrm{~mL}$ of seawater or medium was filtered through $0.2-\mu \mathrm{m}$ syringe filters into $15-\mathrm{ml}$ centrifuge tubes (metal-free, VWR collection) and conserved with $\mathrm{HNO}_{3}$ (1 g, ultrapure).
Samples were diluted $10 \times$ with deionised water before ICPMS analysis. The reported measurements are the average of three technical replicates, with coefficient of variation (CV) of the mean (in \%). In the medium samples, the $\mathrm{CV}$ was $<5 \%$ in all measurements.

Biosilica samples were rinsed with $\mathrm{HNO}_{3}$, transferred to $\mathrm{PF}$ containers and dissolved in concentrated HF acid $(0.18 \mathrm{~mL}$, grade supra pure). The dissolved frustules were diluted with $0.1 \mathrm{M} \mathrm{HNO}_{3}$ before ICP-MS analysis. The reported value is the average of two technical replicates, with CV $1.05 \%$.

The background value of $\mathrm{Ti}$ in Pinnularia frustules was determined from a culture grown in plastic bottles (to avoid any contribution from the glass material itself) but otherwise treated in the same way: The medium was the same as in the Ti uptake experiment (but no Ti was added), and the culture was aerated with pressurized air to promote mixing and gas transport. The background of $\mathrm{Ti}$ in seawater was determined from a sample of water collected from $80-\mathrm{m}$ depth in the Trondheim fiord (the same water was used in the experiments).

\section{Analyses of Si and Ti by TEM}

Transmission electron microscopy characterization was performed with two different instruments: (1) JEOL $2010 \mathrm{~F}$ operated at $200 \mathrm{kV}$ and equipped with an $80-\mathrm{mm}^{2}$ silicon drift detector (SDD) for X-ray energy dispersive spectroscopy (EDS) and (2) double $\mathrm{C}_{\mathrm{s}}$ corrected cold field emission gun JEOL JEM-ARM200F operated at $200 \mathrm{kV}$. This instrument is equipped with a large solid angle Centurio SDD and a Quantum GIF with a dual electron energy loss (EEL) spectrometer. This setup allows for simultaneous acquisition of a high-angle annular dark field (HAADF) scanning transmission electron microscopy (STEM) image in combination with energy dispersive spectroscopy (EDS) and two different EEL regions. Hence, in a spectrum image, an EDS spectrum and two different EEL spectra are acquired and quantified in every pixel of the image.

The TEM samples were prepared by dispersing the frustules on a holey, amorphous carbon-coated $\mathrm{Cu}$ TEM grid. A selection of 21 frustules from the first experiment was analysed (aiming at either a valve or the girdle band zone) by EDS in the JEOL $2010 \mathrm{~F}$ to determine the average Ti concentration. Three frustules with high average Ti concentration were then selected from the second experiment for further analysis using the JEM-ARM200F to map and quantify the Ti concentration with high spatial resolution. Each measurement is the average Ti concentration across a region with a diameter of 1 to $2 \mu \mathrm{m}$ (determined by the size/diameter of the electron beam) on the frustule, pointed at either valve or girdle band zones. 
Analysis of Si and Ti by X-ray photoelectron spectroscopy

Samples were also analysed by X-ray photoelectron spectroscopy (XPS) in order to determine the chemical state of the Ti at the surface and within the bulk of the frustules. A small drop of frustules in methanol was deposited on Al foil and dried. The analysis was performed using an Axis Ultra ${ }^{\text {DLD }}$ XP spectrometer (Kratos Analytical) and monochromatic $\mathrm{Al} \mathrm{K} \alpha$ radiation. Pass energy of $160 \mathrm{eV}$ was used for survey scans and 40-eV high-resolution scans of the individual core levels. Charge neutralization was applied, and the binding energy scale was referenced to the $\mathrm{C} 1 \mathrm{~s}$ component at $285 \mathrm{eV}$. The analysed area was approximately $300 \times 700 \mu \mathrm{m}$. Ion beam sputtering was used to remove surface materials and reveal the bulk composition for analysis. Sputtering was performed using 2-kV Ar ions, and the analysis area after sputtering was approximately $100 \mu \mathrm{m}$ in diameter.

\section{Results}

Growth and physiological status of Pinnularia sp

Under the environmental conditions provided here, the Pinnularia sp. cells maintained a specific growth rate of approximately 0.7 day $^{-1}$, which corresponds to a doubling in cell numbers per day. Cell numbers counted at the start of the experiment was $4.11 \times 10^{4}$ cells $\mathrm{mL}^{-1}$ (S.E. $\pm 0.02, n=2$ ). An average of $1.13 \mathrm{pmol} \mathrm{Si} \mathrm{cell}^{-1}$ was estimated from several measurements during the experiment $( \pm 0.07, \mathrm{CV}=5.87 \%)$. A major fraction of the added $\mathrm{Si}$ was consumed during the first $24 \mathrm{~h}$ of the experiment or shortly after, corresponding to a biomass yield of approximately $4.20-10^{4}$ new cells $\mathrm{mL}^{-1}$, i.e. a doubling in biomass within the experimental period. $F_{\mathrm{t}}$ measurements showed a doubling also in fluorescence and corroborated a twofold increase in biomass during the experiment. $Q_{\mathrm{Y}}$ is a measurement of the efficiency of conversion of absorbed light into photochemistry, and it is used to assess the photophysiological status of the cells. $Q_{\mathrm{Y}}$ was 0.42 at the beginning of the experiment, indicating that the cells were in a reasonably healthy photophysiological state despite the $\mathrm{Si}$ deprivation previous to the experimental starting time (data not shown). The $Q_{\mathrm{Y}}$ then decreased to 0.30 during the $10 \mathrm{~h}$ of $\mathrm{Ti} / \mathrm{Si}$ addition and thereafter increased to 0.37 where it remained stable for $48 \mathrm{~h}$. When there was less than $1 \mu \mathrm{mol}$ $\mathrm{Si} \mathrm{L}^{-1}$ in the medium, the $Q_{\mathrm{Y}}$ sank to 0.25 , indicating that the photophysiological condition was challenged.

Dissolved $\mathrm{Si}$ and $\mathrm{Ti}$ in the cultures

A total of $48.6 \pm 0.3(\mathrm{SE}, n=2) \mu \mathrm{mol} \mathrm{Si} \mathrm{\textrm {L } ^ { - }}$ of culture was added drop-wise to the experimental cultures during the first
$10 \mathrm{~h}$ of the experiment, and $75 \%$ of the added Si was removed from the medium by the cells during the first $24 \mathrm{~h}$ (Fig. 1). After $48 \mathrm{~h}$, the dissolved $\mathrm{Si}(\mathrm{dSi})$ was low $(1 \mu \mathrm{M})$, the biomass had ceased to increase and the experiment was terminated after $72 \mathrm{~h}$. Simultaneously to the $\mathrm{Si}$ addition, $2.84 \pm$ $0.01 \mu \mathrm{mol} \mathrm{Ti} \mathrm{L}{ }^{-1}$ (SE, $\left.n=2\right)$ was added drop-wise to the experimental cultures. After $24 \mathrm{~h}$, the medium contained only $0.086 \mu \mathrm{mol} \mathrm{Ti} \mathrm{L}{ }^{-1}$ (i.e. $97 \%$ was taken up; Fig. 1). The background of $\mathrm{Ti}$ in the seawater used was $0.0064 \mu \mathrm{M}$ $( \pm 0.0001 \mathrm{SE}, n=3)$ but somewhat higher in $\mathrm{f} / 2$ medium due to impurities in chemicals used to amend the seawater: $0.0094 \mu \mathrm{M}( \pm 0.0001 \mathrm{SE}, n=3)$. A control experiment without

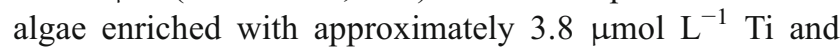
$160 \mu \mathrm{mol} \mathrm{L}{ }^{-1} \mathrm{Si}$ showed that both $\mathrm{Si}$ and $\mathrm{Ti}$ stayed in the solution after 24 and $48 \mathrm{~h}$. The concentrations measured were somewhat lower than the added dose, but not more than $10 \%$ and within the errors in analysis and dosage of $\mathrm{Si}$ and $\mathrm{Ti}$ added.

\section{$\mathrm{Si}$ and $\mathrm{Ti}$ in frustules}

The ICP-MS analysis showed that a sample of frustules grown in plastic flasks with $\mathrm{f} / 2$ medium and no Ti added contained $0.001 \mu \mathrm{M}$ Ti (CV $17.7 \%$ ), which is comparable to the concentration of $\mathrm{Ti}$ observed in $\mathrm{f} / 2$ medium. A doubling of the biomass and concomitant removal of $2.76 \mu \mathrm{mol} \mathrm{Ti} \mathrm{L}{ }^{-1}$ of culture within the first $24 \mathrm{~h}$ of the experiment indicated a cellular content of $33.2 \mathrm{fmol} \mathrm{Ti}$ per cell in the new cells or $2.37 \mathrm{wt} . \% \mathrm{Ti} / \mathrm{SiO}_{2}$ (average over all frustules, not considering the difference between old and new valves, see the following related discussion). A low-resolution, bright-field TEM image (Fig. 2a) and a medium-resolution high-angle annular dark field (HAADF) scanning TEM (STEM) image (Fig. 2b) show the cleaned frustules with characteristic patterns of ribs and pores. The high-resolution HAADF STEM image of an area

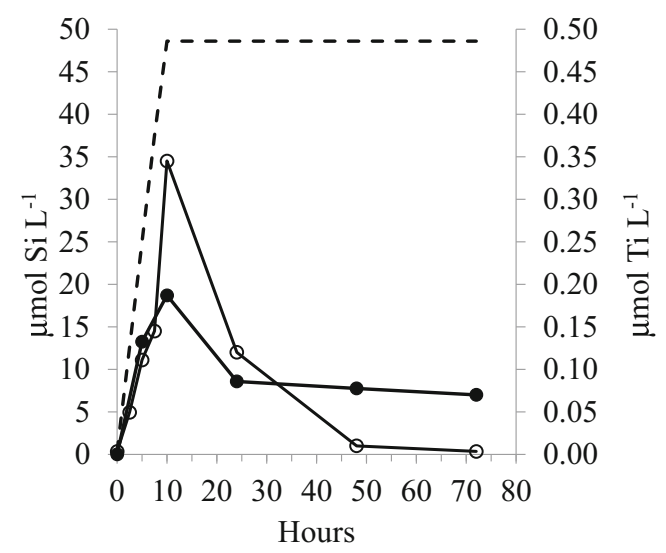

Fig. 1 Dissolved $\mathrm{Si}\left(\mu \mathrm{mol} \mathrm{L} \mathrm{L}^{-1}\right.$, open circles $)$ and dissolved $\mathrm{Ti}\left(\mu \mathrm{mol} \mathrm{L} \mathrm{L}^{-1}\right.$, filled circles) in the culture. The dotted line shows the addition of Si and $\mathrm{Ti}$ (calculated, not measured), which were added drop-wise for the first $10 \mathrm{~h}$ 
Fig. 2 a Low-resolution, brightfield TEM image of cleaned Pinnularia frustules from one of the Ti uptake experiments. b Section of a Pinnularia sp. valve with pores. c High annular dark field (HAADF) scanning transmission electron spectroscopy (STEM) image of an area which includes four pore openings and surrounding $\mathrm{SiO}_{2}$. The boxes indicate where EDS/ EELS measurements were performed, and in the four pore areas the average $\mathrm{Ti}$ was 1.06 $( \pm 0.101)$ at.\%. In the two areas between the pores, the Ti was $0.21( \pm 0.050)$ at. $\%$. d High annular dark field (HAADF) scanning transmission electron spectroscopy (STEM) image of one of the pores showing the granular appearance of the amorphous $\mathrm{SiO}_{2}$
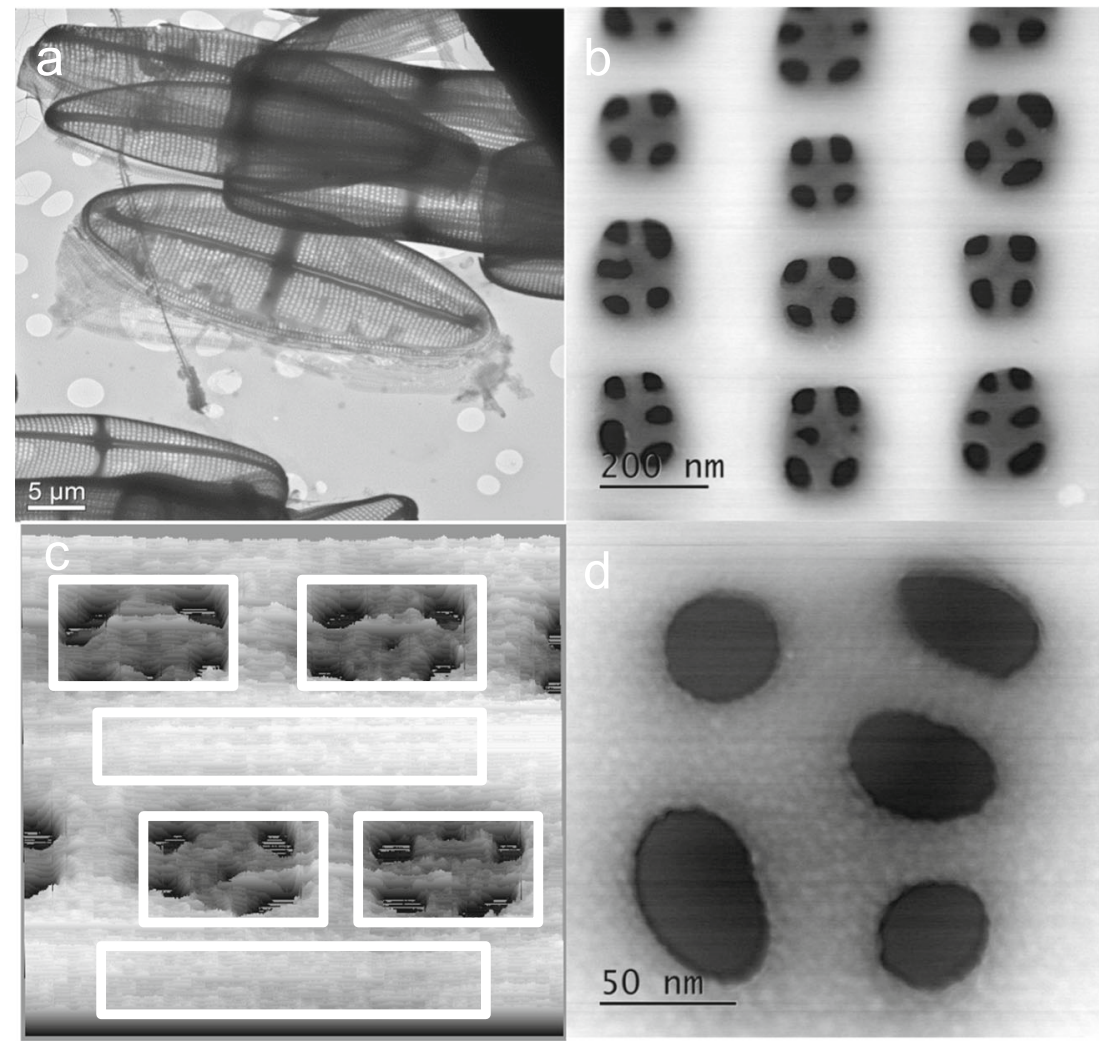

of pores revealed the granular surface of amorphous $\mathrm{SiO}_{2}$, with particles of 4 to $5 \mathrm{~nm}$ in diameter (Fig. 2d).

EDS analysis of 21 randomly selected frustules gave an average atomic $\mathrm{O} / \mathrm{Si}$ ratio of $2.04 \pm 0.19(\mathrm{SD})$, not significantly different from $2(p=0.357)$. The EDS analysis showed $\mathrm{Si}$ contents of 29 to 37 at.\%, with an average of 33 at.\% ( \pm 2 SD). A quantile plot suggested good fit (assuming a normal distribution) for the Si content (linear relationship; Fig. 3a). Ti content was from 0 to 0.55 at. $\%$, with an average of 0.23 at. $\%$ $( \pm 0.20 \mathrm{SD})$ over all the frustules. Based on a quantile plot, the Ti content showed a bi- or tri-phased relationship consistent with a model of old valves with low Ti content and new valves (synthesised during the experiment) with high $\mathrm{Ti}$ content
(Fig. 3a). The results also showed that there was an enrichment of Ti by a factor of 13 due to Ti addition: average Ti content of old valves was $0.023 \pm 0.017$ at.\%, compared to $0.300 \pm 0.148$ at. $\%$ in new valves. The atomic ratios of $\mathrm{Ti} / \mathrm{Si}$ in the 21 measurements were from 0 to 0.019 (Fig. 3b), and the distributions of $\mathrm{Si}$ and $\mathrm{Ti}$ were confirmed by Shapiro-Wilk test for normality with $p=0.994$ and $p=0.009$ for $\mathrm{Si}$ and Ti, respectively.

In order to provide finer detail about Ti distribution, three frustules with relatively high Ti concentrations were selected for high-spatial-resolution elemental mapping by simultaneous EDS and EELS. The EDS element maps from the three frustules showed significant differences between the Ti
Fig. 3 a Quantile plot based on the assumption of normal distribution of elements in 21 cleaned valves from Pinnularia sp. The linear fit confirms normal distribution of $\mathrm{Si}$ (open circles). The distribution of Ti is bi- or triphasic and confirms the different quantities of Ti in old vs. new valves (filled circles). The distribution was tested using Shapiro-Wilks test for normality, and $p=0.994$ and 0.009 for $\mathrm{Si}$ and $\mathrm{Ti}$, respectively. $\mathbf{b} \mathrm{Ti} / \mathrm{Si}$ ratios (atomic) in the 21 cleaned valves




Table 1 Oxygen, silicon and titanium (at.\%) and ratio of $\mathrm{Ti}$ to $\mathrm{Si}$ measured by EDS in either pores or rib area on cleaned valves of Pinnularia sp. The values are average of measurements (with STD in parenthesis) from three frustules that showed high Ti content

\begin{tabular}{llllll}
\hline & $\mathrm{O}$ & $\mathrm{Si}$ & $\mathrm{Ti}$ & $\mathrm{Ti} / \mathrm{Si}$ & Number, $n$ \\
\hline Pores & $67.8(2.30)$ & $31.2(2.29)$ & $1.06(0.101)$ & 0.034 & 10 \\
Ribs & $68.0(1.62)$ & $31.8(1.56)$ & $0.21(0.050)$ & 0.007 & 4 \\
\hline
\end{tabular}

concentration in the pore linings and in the thicker $\mathrm{SiO}_{2}$ regions between the pores (Fig. 2c). The Ti concentration in the thin pore lining regions was $>1$ at. $\%$, i.e. five times more Ti than in the thicker regions between the pores (Table 1). EELS measurements confirmed the inhomogeneous distribution of $\mathrm{Ti}$ in the biosilica with 0.00 at.\% $\mathrm{Ti}$ in the bulk $\mathrm{SiO}_{2}$ (between pore areas) and 1.57 at.\% Ti in the pore area/linings. The difference was evident also after correction for the variations in frustule thickness over the analysis area (Fig. 4). The energy loss spectra show the $\mathrm{O} \mathrm{K}$ top around $540 \mathrm{eV}$ present in both the pore region and the region between pores, while the Ti L2 and L3 tops (around 455-465 eV) are only present in the spectrum from the pore region (Fig. 5).

A XPS survey spectrum showed that, besides Si and O, C, $\mathrm{N}, \mathrm{Na}$ and Ti were present as peaks that are associated with the surface of the frustules (Fig. 6a). The presence of $\mathrm{Al}$ and a proportion of the $\mathrm{O}$ signal are associated with the $\mathrm{Al}$ support foil. High-energy resolution scans from the Ti $2 p$ peak region (Fig. 6b) before and after sputtering suggested the presence of $\mathrm{Ti}_{2} \mathrm{O}_{3}$ or $\mathrm{TiO}$ in the valve ( $\mathrm{Ti} 2 \mathrm{p} 1 / 2 \sim 463$ and $\mathrm{Ti} 2 \mathrm{p} 3 / 2 \sim$ $457 \mathrm{eV}$ ); after sputtering, the Ti peaks were consistent with the presence of $\mathrm{TiO}_{2}(\mathrm{Ti} 2 \mathrm{p} 1 / 2 \sim 464$ and $\mathrm{Ti} 2 \mathrm{p} 3 / 2 \sim 458 \mathrm{eV})$. The Si peak is consistent with the expected $\mathrm{SiO}_{2}$ composition, Si $2 p \sim 103 \mathrm{eV}$.

\section{Discussion}

Bioincorporation of $\mathrm{Si}$ in combination with other elements such as $\mathrm{Ti}, \mathrm{Ge}$ or $\mathrm{Zn}$ is considered as a means to modulate the material properties of diatom frustules for use in solar cell technology. However, processes of element uptake and biosilicification must be understood in more detail before we are able to control the processes. Ti concentrations in the oceans are in the picomolar range, and natural marine phytoplankton contains up to 0.078 at.\% $\mathrm{Ti}$ in the silica fraction (Martin and Knauer 1973). This is comparable to the lower amounts of Ti measured in the valves in our study (0.010.06 at.\%), presumably the old valves that were produced prior to the Ti addition. The TEM images from this experiment show normally developed frustules without any obvious aberrations in the frustule shape or pore pattern, and thus growth in Ti-supplemented medium did not seem to interfere with the normal cell cycle and frustule synthesis. This was also supported by the measurements of fluorescence and quantum yield, which showed a doubling of the biomass and satisfactory photosynthetic performance during the first $24 \mathrm{~h}$ of the uptake experiment. From our measurements, the removal of Ti from the medium seemed to proceed with a rate proportional to that of $\mathrm{Si}$, but how $\mathrm{Ti}$ is taken up or how fast it is taken up by the cells remains unknown. Based on the chemical similarities of $\mathrm{Si}(\mathrm{OH})_{4}$ and $\mathrm{Ti}(\mathrm{OH})_{4}$, it is reasonable to assume that $\mathrm{Ti}$ is taken up via the same transport system as $\mathrm{Si}$, but not necessarily in a constant or foreseeable ratio. Our study of Ti uptake and bioincorporation in Pinnularia sp. confirm that $\mathrm{Ti}$ is incorporated together with $\mathrm{Si}$ in the new frustules, in accordance with Jeffryes et al. (2008).

From our data, we see that there is a higher concentration of Ti around the pores on the valves (1.06 at.\%), which is similar to the amounts and distribution patterns observed by Jeffryes et al. (2008). Our measurements include a correction for the uneven frustule thickness (Fig. 4) which Jeffryes et al. (2008) lacked, and the inhomogeneous distribution of $\mathrm{Ti}$ is therefore confirmed by our data. The fact that Ti is inhomogeneously distributed and concentrated around pores can be of use, for example, to enhance photon transport via the nano-scaled pores. If we understand why this happens, it would increase the possibility of biogenic manufacturing to produce frustules with special properties. Jeffryes et al. (2008) speculated that more Ti was deposited in the final stages of silica deposition due to Si pool exhaustion and slower rates of condensation of
Fig. 4 EDS thickness map (left) used to correct the EELS Ti map for thickness variations over the valve and pores; the resulting $3 \mathrm{D}$ image (right) shows the increased amounts of Ti localized around the pore openings in the Pinnularia sp. valve

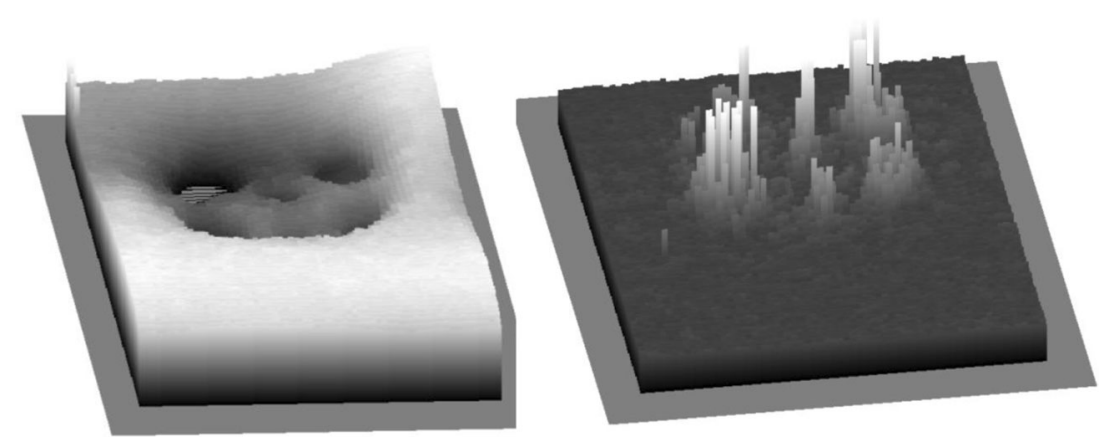


Fig. 5 EELS data from pore region (green square and line) and between pores (red square and line) showing the $\mathrm{O} \mathrm{K}$ peak around $540 \mathrm{eV}$ present in both regions, while Ti L2 and Ti L3 $(455-465 \mathrm{eV})$ are only observed in the spectra from the pore region
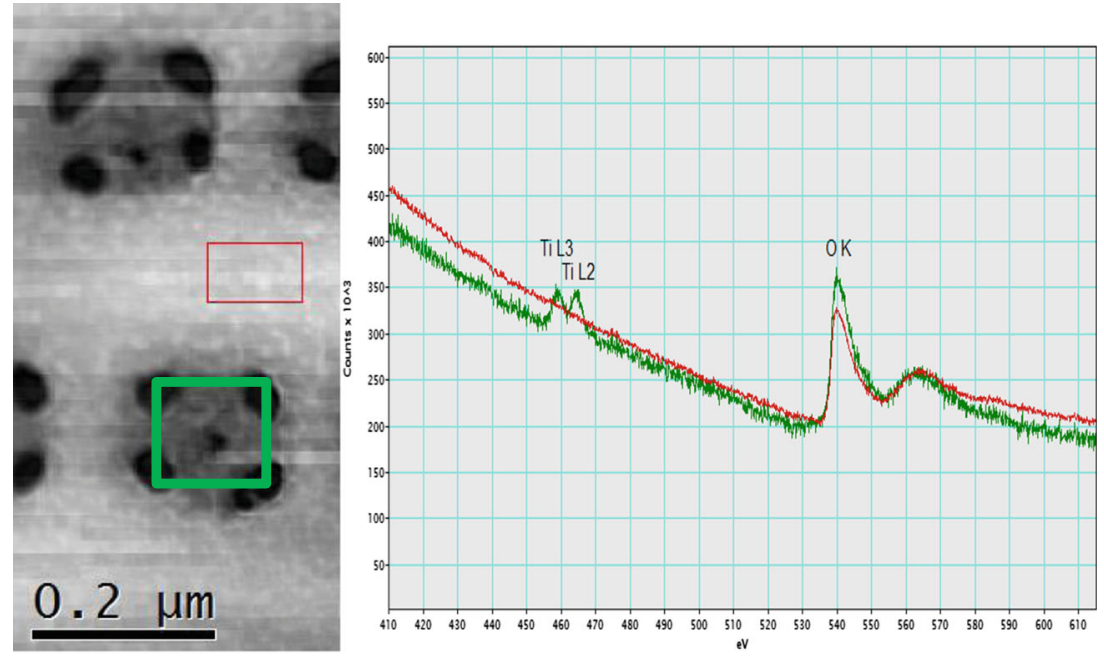

Ti to $\mathrm{TiO}_{2}$. In our experiment, the first generation of cells produced with $\mathrm{Ti}$ enrichment were not Si-limited and the $\mathrm{Si}$ pools therefore presumably non-exhausted (Fig. 1). Ti and Si were available in the culture medium in an atomic ratio of 0.10 in the beginning of the experiment, and when the addition of $\mathrm{Ti}$ and $\mathrm{Si}$ stopped after $10 \mathrm{~h}$, the ratio changed to 0.06 . Using the removed $\mathrm{Ti}$ and $\mathrm{Si}$ to estimate the intracellular pools, it seems that the ratio was high and stable $(0.17-0.19)$ during the $10 \mathrm{~h}$ of Ti and $\mathrm{Si}$ addition. This time frame is coincident with finalization of the frustule and cell separation into two individual daughter cells in the cells that were synchronized due to Si depletion and the beginning of frustule synthesis in the next generation of cells (and concomitantly active Si uptake). The ratio sank to $0.06-0.08$ from $24 \mathrm{~h}$, and the next generation would then have a lower intracellular pool at the time when they finalize the fine structures of the frustules. Another explanatory model that is not related to concentrations of $\mathrm{Ti}$ and Si during the frustule synthesis period is that the uneven distribution of $\mathrm{Ti}$ in the frustules may be caused by the chemical quality of micelles or moulding structures involved in silica deposition and pore construction during frustule synthesis. Synthesis of the new valves in raphid pennate diatoms such as Pinnularia sp. starts from the central raphe and then proceeds outwards with ribs and crossing connections that form pores (Sato et al. 2011; Cox et al. 2012), using the cytoskeleton actin microfilaments to direct the deposition. Silica is deposited in micro-fibrils radiating out from a midline and bi-directionally towards the valve surfaces, and the raphe opening and the areolar pores are lined afterwards with a thick layer of silica that is more resistant to alkaline etching (Crawford et al. 2009). The processes that lead to the differentiation between the micro-fibrillar silica construction and the thick lining around openings have not been revealed, but increased concentration of $\mathrm{Ti}$ in these lining areas may be connected to these processes. Also, fluidic phase-separation theories and mathematical modelling have been used to show how the frustule architecture and pore pattern can arise by physio-chemical processes involving, e.g., polyamine micelles (Sumper 2002; Lenoci and Camp 2008; Willis et al. 2013), yet another explanatory model suggests that pores are constructed from molecular scaffolds or moulding structures onto which the $\mathrm{Si}$ is deposited or the scaffold creates an obstacle so that the Si deposition is interrupted at certain places, thus creating the pore patterns (Tesson and Hildebrand 2013). The exact composition of the scaffolds or moulding structures is not known, but chitin is found in close association with centric diatom valves and may play a role as a moulding agent (Brunner et al. 2009; Durkin et al. 2009).

The HAADF STEM image of a pore detail (Fig. 2d) revealed surface structures or particles of approximately 4 to $5 \mathrm{~nm}$, which is very interesting considering that this is considerably smaller than the reported sizes of $\mathrm{SiO}_{2}$ precipitates made with natural diatom proteins. If the polymerization of $\mathrm{Si}$ occurs without salts or other ions present, colloidal particles of 2 to $3 \mathrm{~nm}$ in size are formed, and further development is dependent on $\mathrm{pH}$ and temperature (Coradin and Lopez 2003). Ions such as $P$, however, are known to influence the particle size of Si precipitates in vitro (Sumper et al. 2003), and Si particle size in frustules of living cells is also related to the different polyamines and proteins involved in Si precipitation (Kroger et al. 1999). A study by Lechner and Becker (2014) showed that different synthetic peptides resembling silaffins produced $\mathrm{Si}$ spheres of different sizes and also of different surface graininess depending on the numbers and positioning of lysine residues on the peptide. It is possible that we observed a grainy surface of larger Si polymers in the frustule surface. Also, Vertegel et al. (2004) demonstrated that the protein lysozyme adsorbed to Si nanoparticles of different sizes, and increasing particle size (40 or $100 \mathrm{~nm}$ ) led to a higher degree of unfolding in the protein and concomitant decrease in activity. On small Si particles of $4 \mathrm{~nm}$ in diameter, however, the lysozyme did not unfold, and the activity was 
Fig. 6 a XPS analysis of cleaned Pinnularia sp. frustules on an Al foil showing the overall surface composition of the frustules after drying. b The effect of Ar ion sputtering on the Ti $2 \mathrm{p}$ (left panel) and Si $2 \mathrm{p}$ (right panel) peaks; the initial analysis is shown in the lower curve, and the upper curve shows the analysis of the same area after Ar ion sputtering. The peaks appear in the same energy regions as in a but with the signal acquired from a smaller area for more detail
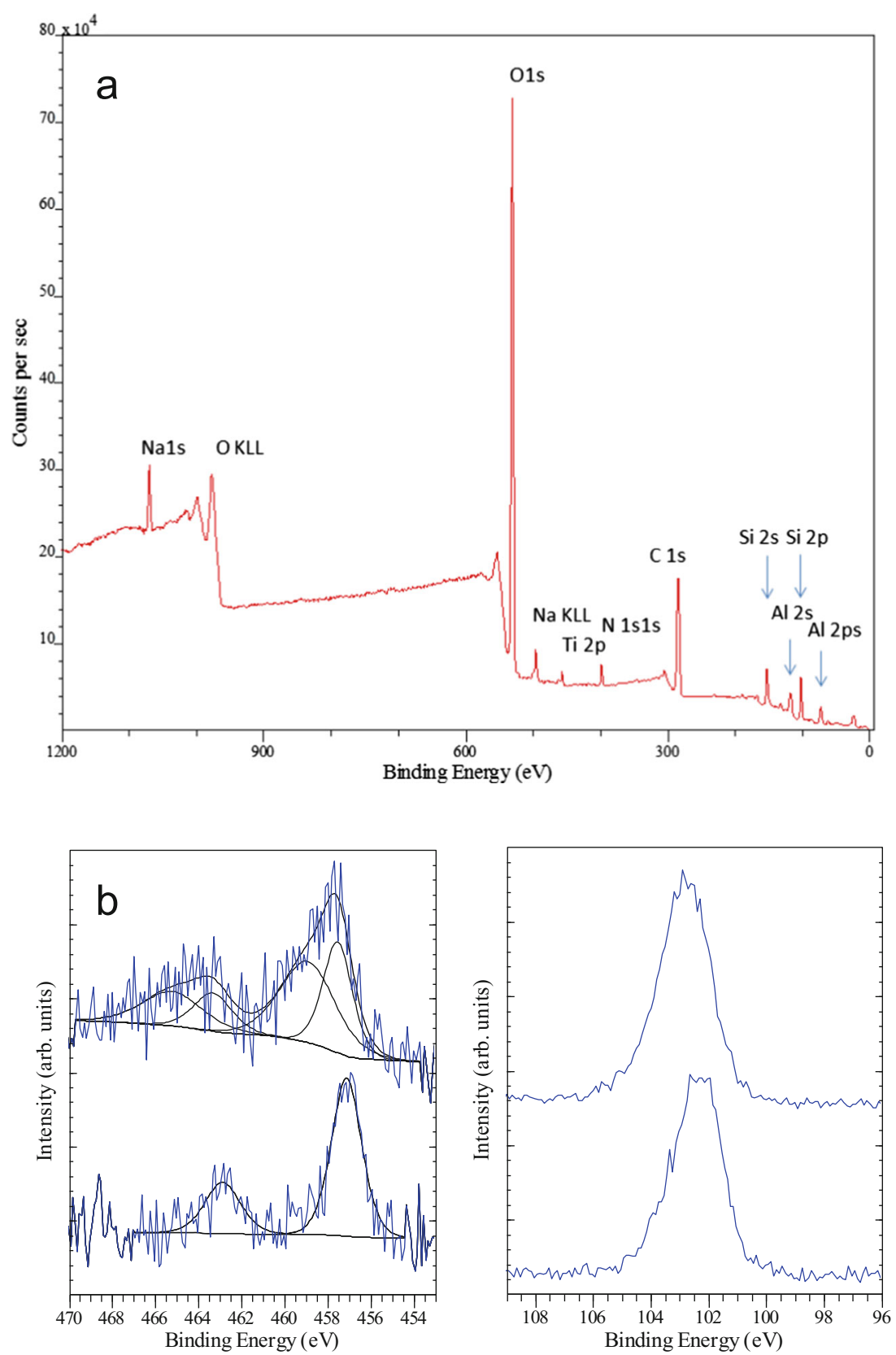

higher. The relation between the proteins involved in biosilification and particle sizes is not fully understood, but a similar mechanism with small particles and enhanced protein activity could play a role also in frustule synthesis.

EDS analysis was used to analyse the amounts of $\mathrm{Ti}$ in the biosilica, and the distribution of $\mathrm{SiO}_{2}$ showed a good fit with the assumption of normal distribution. Ti, on the other hand, was distributed in a bi- or even tri-phasic pattern (Fig. 3), and this observation is related to the occurrence of valves from different times in the culture period. Some valves are old (mother valves from before $\mathrm{Ti}$ addition), and other valves are newly synthesised "daughters" with $\mathrm{Ti}$ incorporated in the biosilica. The quantification of $\mathrm{TiO}_{2}$ around pores was considered approximate in the work of Jeffryes et al. (2008) due to scattering of the X-ray beam in the sample. In our measurements, higher spatial resolution was achieved by the application of EELS, and both EDS and EELS showed similar trends qualitatively with increased $\mathrm{Ti}$ around the pore linings and less $\mathrm{Ti}$ in the solid areas of biosilica between pores. The EELS measurements, however, indicated that the difference in Ti concentration from the pore regions to the regions between the pores is even larger than those quantified by EDS. This is because the EDS analysis suffered from stray radiation due to backscattered and diffracted electrons that hit other parts of the 
sample than the region illuminated by the beam. EELS measurements, on the other hand, do not suffer from such stray signals.

The XPS analysis of valves from the Ti incorporation experiment verified the presence of $\mathrm{TiO}_{2}$ in the bulk material of the valve before and after sputtering, and quantification of the peak areas gave a Ti/Si atomic ratio of $\sim 0.05$ (at). These results are consistent with the data from Lang et al. (2013) and Chrcanovic et al. (2012). High-energy resolution scans showed that the $\mathrm{Si}$ peak is consistent with the expected $\mathrm{SiO}_{2}$ composition, also after sputtering. A component of the Ti $2 p$ peak appears at higher binding energy, which is indicative of a higher oxidation state such as $\mathrm{Ti}_{2} \mathrm{O}_{3} / \mathrm{Ti}^{3+}$ (Fig. 6b). There was a slight shift of $0.5-1 \mathrm{eV}$ compared to the peaks measured before sputtering, but we cannot say with certainty from our data that the valve surface contains $\mathrm{Ti}_{2} \mathrm{O}_{3}$ or TiO. These results are difficult to interpret unambiguously due to charge compensation effects and the influence of the ion beam on the surface chemistry. The analysis is consistent with the presence of $\mathrm{Ti}^{3+}$ in the frustules, allowing for some uncertainty due to damage caused by the ion beam. The energy shift between oxidised and metallic Ti, however, is $\sim 5 \mathrm{eV}$, and allowing for the uncertainty in energy reference, it is regarded as large enough to eliminate the possibility of a metallic component in the spectra. Mayer et al. (1995) described the influence of ion damage on the XPS spectrum obtained from $\mathrm{TiO}_{2}$ thin films. There are few studies of the biochemistry of $\mathrm{Ti}$ in cells or frustules (Buettner and Valentine 2012), but different Ti oxidation states in the frustule surface layers may be a result of the biochemical processes leading to the incorporation of $\mathrm{Ti}$ in the $\mathrm{SiO}_{2}$ or post-incorporation chemical modifications due to, e.g., cleaning with SDS, sample storage or exposure to air during the analyses. The presence of other elements such as $\mathrm{C}$, $\mathrm{N}$ or $\mathrm{Na}$ can be related to remnants of organic molecules that were involved in the frustule synthesis (e.g. N-rich polyamines) and therefore tightly integrated into the $\mathrm{SiO}_{2}$. The SDS cleaning used here is considered a mild cleaning process that does not remove completely all the organic components of the valve. It is also possible that the organic remnants stem from other sources, and for example, adsorption of hydrocarbon or carbon oxygen species from the air onto the Ti surface of dental implants is known (Chrcanovic et al. 2012).

Our data confirm the uptake and incorporation of Ti into diatom nanostructures, and a relatively high doping effect is achieved in the pore lining areas. The inhomogeneous distribution of the element influences the application of Ti-doped frustules in, e.g., solar cell technology, and how this effect can be exploited needs more investigations into the material technological properties.

Acknowledgments This work is part of the project "SOLBIOPTABiotechnological Production of Materials for Optimized Solar Cell Efficiency" that received funding from the Norwegian Research Council (project no. 200013). We thank Syverin Lierhagen at Department of Chemistry/NTNU for help with the ICP-MS analyses.

Open Access This article is distributed under the terms of the Creative Commons Attribution License which permits any use, distribution, and reproduction in any medium, provided the original author(s) and the source are credited.

\section{References}

Annenkov VV, Basharina TN, Danilovtseva EN, Grachev MA (2013) Putative silicon transport vesicles in the cytoplasm of the diatom Synedraacus during surge uptake of silicon. Protoplasma 250:11471155

Aw MS, Simovic S, Yu Y, Addai-Mensah J, Losic D (2012) Porous silica microshells from diatoms as biocarrier for drug delivery applications. Powder Technol 223:52-58

Basharina TN, Danilovtseva EN, Zelinskiy SN, Klimenkov IV, Likhoshway YV, Annenkov VV (2012) The effect of titanium, zirconium and tin on the growth of diatom Synedraacus and morphology of its silica valves. Silicon 4:239-249

Brunner E, Groeger C, Lutz K, Richthammer P, Spinde K, Sumper M (2009) Analytical studies of silica biomineralization: towards an understanding of silica processing by diatoms. Appl Microbiol Biotechnol 84:607-616

Brzezinski MA, Olson RJ, Chisholm SW (1990) Silicon availability and cell-cycle progression in marine diatoms. Mar Ecol Prog Ser 67:83-96

Buettner KM, Valentine AM (2012) Bioinorganic chemistry of titanium. Chem Rev 112:1863-1881

Chrcanovic BR, Pedrosa AR, Martins MD (2012) Chemical and topographic analysis of treated surfaces of five different commercial dental titanium implants. Mater Res 15:372-382

Cole KE, Ortiz AN, Schoonen MA, Valentine AM (2006) Peptide- and long-chain polyamine-induced synthesis of micro- and nanostructured titanium phosphate and protein encapsulation. Chem Mater 18:4592-4599

Coradin T, Lopez PJ (2003) Biogenic silica patterning: simple chemistry or subtle biology? Chembiochem 4:251-259

Cox EJ, Willis L, Bentley K (2012) Integrated simulation with experimentation is a powerful tool for understanding diatom valve morphogenesis. Biosystems 109:450-459

Crawford SA, Chiovitti A, Pickett-Heaps J, Wetherbee R (2009) Micromorphogenesis during diatom wall formation produces siliceous nanostructures with different properties. J Phycol 45:1353-1362

De Stefano L, Maddalena P, Moretti L, Rea I, Rendina I, De Tommasi E, Mocella V, De Stefano M (2009) Nano-biosilica from marine diatoms: a brand new material for photonic applications. Superlattice Microst 46:84-89

Del Amo Y, Brzezinski MA (1999) The chemical form of dissolved Si taken up by marine diatoms. J Phycol 35:1162-1170

Durkin CA, Mock T, Armbrust EV (2009) Chitin in diatoms and its association with the cell wall. Eukaryot Cell 8:1038-1050

Gale DK, Jeffryes C, Gutu T, Jiao J, Chang C-h, Rorrer GL (2011) Thermal annealing activates amplified photoluminescence of germanium metabolically doped in diatom biosilica. J Mater Chem 21: 10658-10665

He J, Chen D, Li Y, Shao J, Xie J, Sun Y, Yan Z, Wang J (2013) Diatomtemplated $\mathrm{TiO}_{2}$ with enhanced photocatalytic activity: biomimetics of photonic crystals. Appl Phys A: Mater Sci Process 113:327-332

Hildebrand M (2008) Diatoms, biomineralization processes, and genomics. Chem Rev 108:4855-4874

Jeffryes C, Gutu T, Jiao J, Rorrer GL (2008) Metabolic insertion of nanostructured $\mathrm{TiO}_{2}$ into the patterned biosilica of the diatom 
Pinnularia sp by a two-stage bioreactor cultivation process. ACS Nano 2(10):2103-2112

Jeffryes C, Campbell J, Li H, Jiao J, Rorrer G (2011) The potential of diatom nanobiotechnology for applications in solar cells, batteries, and electroluminescent devices. Energy Environ Sci 4:3930 3941

Kinrade SD, Gillson AME, Knight CTG (2002) Silicon-29 NMR evidence of a transient hexavalent silicon complex in the diatom Naviculapelliculosa. J Chem Soc Dalton Trans 3:307-309

Kroger N, Deutzmann R, Sumper M (1999) Polycationic peptides from diatom biosilica that direct silica nanosphere formation. Science 286:1129-1132

Kroger N, Dickerson MB, Ahmad G, Cai Y, Haluska MS, Sandhage KH, Poulsen N, Sheppard VC (2006) Bioenabled synthesis of rutile $\left(\mathrm{TiO}_{2}\right)$ at ambient temperature and neutral $\mathrm{pH}$. Angew Chem Int Ed 45:7239-7243

Lang Y, del Monte F, Rodriguez BJ, Dockery P, Finn DP, Pandit A (2013) Integration of $\mathrm{TiO}_{2}$ into the diatom Thalassiosira weissflogii during frustule synthesis. Sci Rep 3

Lechner CC, Becker CFW (2014) A sequence-function analysis of the silica precipitating silaffin R5 peptide. J Pept Sci 20:152-158

Lenoci L, Camp PJ (2008) Diatom structures templated by phaseseparated fluids. Langmuir 24:217-223

Li N, Sioutas C, Cho A, Schmitz D, Misra C, Sempf J, Wang MY, Oberley T, Froines J, Nel A (2003) Ultrafine particulate pollutants induce oxidative stress and mitochondrial damage. Environ Health Perspect 111:455-460

Mao L, Liu J, Zhu S, Zhang D, Chen Z, Chen C (2014) Sonochemical fabrication of mesoporous $\mathrm{TiO}_{2}$ inside diatom frustules for photocatalyst. Ultrason Sonochem 21:527-534

Martin JH, Knauer GA (1973) Elemental composition of plankton. Geochim Cosmochim Acta 37:1639-1653

Mayer JT, Diebold U, Madey TE, Garfunkel E (1995) Titanium and reduced titania overlayers on titanium dioxide (110). J Electron Spectrosc Relat Phenom 73:1-11

Miller RJ, Bennett S, Keller AA, Pease S, Lenihan HS (2012) $\mathrm{TiO}_{2}$ nanoparticles are phototoxic to marine phytoplankton. PLoS ONE 7(1)

Mock T, Samanta MP, Iverson V, Berthiaume C, Robison M, Holtermann K, Durkin C, BonDurant SS, Richmond K, Rodesch M, Kallas T, Huttlin EL, Cerrina F, Sussmann MR, Armbrust EV (2008) Wholegenome expression profiling of the marine diatom Thalassiosira pseudonana identifies genes involved in silicon bioprocesses. Proc Natl Acad Sci U S A 105:1579-1584
Sato S, Watanabe T, Nagumo T, Tanaka J (2011) Valve morphogenesis in an araphid diatom Rhaphoneisamphiceros (Rhaphoneidaceae, Bacillariophyta). Phycol Res 59:236-243

Sclafani M, Juffmann T, Knobloch C, Arndt M (2013) Quantum coherent propagation of complex molecules through the frustule of the alga Amphipleurapellucida. New J Phys 15

Shea R, Chopin T (2007) Effects of germanium dioxide, an inhibitor of diatom growth, on the microscopic laboratory cultivation stage of the kelp, Laminariasaccharina. J Appl Phycol 19:27-32

Spinde K, Pachis K, Antonakaki I, Paasch S, Brunner E, Demadis KD (2011) Influence of polyamines and related macromolecules on silicic acid polycondensation: relevance to "soluble silicon pools"? Chem Mater 23:4676-4687

Sumerel JL, Yang WJ, Kisailus D, Weaver JC, Choi JH, Morse DE (2003) Biocatalytically templated synthesis of titanium dioxide. Chem Mater 15:4804-4809

Sumper M (2002) A phase separation model for the nanopatterning of diatom biosilica. Science 295:2430-2433

Sumper M, Lorenz S, Brunner E (2003) Biomimetic control of size in the polyamine-directed formation of silica nanospheres. Angew Chem Int Ed 42:5192-5195

Tesson B, Hildebrand M (2013) Characterization and localization of insoluble organic matrices associated with diatom cell walls: insight into their roles during cell wall formation. PLOS ONE 8(4)

Thamatrakoln K, Hildebrand M (2007) Analysis of Thalassiosira pseudonana silicon transporters indicates distinct regulatory levels and transport activity through the cell cycle. Eukaryot Cell 6:271279

Toster J, Iyer KS, Xiang W, Rosei F, Spiccia L, Raston CL (2013) Diatom frustules as light traps enhance DSSC efficiency. Nanoscale 5:873876

Vertegel AA, Siegel RW, Dordick JS (2004) Silica nanoparticle size influences the structure and enzymatic activity of adsorbed lysozyme. Langmuir 20:6800-6807

Willis L, Cox EJ, Duke T (2013) A simple probabilistic model of submicroscopic diatom morphogenesis. J Roy Soc Interface 10(83)

Yamanaka S, Yano R, Usami H, Hayashida N, Ohguchi M, Takeda H, Yoshino K (2008) Optical properties of diatom silica frustule with special reference to blue light. J Appl Phys 103(7)

Zurzolo C, Bowler C (2001) Exploring bioinorganic pattern formation in diatoms. A story of polarized trafficking. Plant Physiol 127:13391345 